The emergent curriculum: navigating a complex course between unguided learning and planned enculturation

Deborah Osberg and Gert Biesta (2008)

J ournal of Curriculum Studies, 40:3, $313-328$

URL: http://dx.doi.org/10.1080/00220270701610746 


\title{
The emergent curriculum: navigating a complex course between unguided learning and planned enculturation
}

\author{
Deborah Osberg and Gert Biesta
}

\begin{abstract}
This study uses the 'logic' of emergence to rethink the practice and purposes of modern Western schooling which, conventionally, is organized around a representational epistemology and aims to enculture the student into a particular way of being. The idea of 'planned enculturation' is, however, problematic for contemporary multicultural societies for it raises the question of which or whose culture should be promoted through schooling. The authors argue that emergentist challenges to representational epistemology have not released schooling from its problematic function of planned enculturation. However, if the logic of emergence is applied not only to knowledge but also to human subjectivity then the educational problem of planned enculturation disappears. When emergentist logic is applied in this double sense, it becomes possible to understand the primary responsibility of the educator not as a responsibility to promote a particular way of being, but as a responsibility to the singularity and uniqueness of each individual student. If this is what counts as 'educational responsibility' then this would distinguish 'responsible' educational practices from unguided learning on the one hand and practices of planned enculturation/socializa-tion (training) on the other.
\end{abstract}

With the advent of constructivist, pragmatist, and post-structuralist epistemologies, as well as 'emergentist' epistemologies derived from complexity theory, comes the idea that knowledge is neither a representation of something more 'real' than itself, nor an 'object' that can be transferred from one place to the next. 'Knowledge is understood, rather, to 'emerge' as we, as human beings, participate in the world. Knowledge, in other words, does not exist except in our participatory actions. With complexity, furthermore, we can understand every meaning that emerges as uniquely new, something which has not been in the world before, and which cannot be predicted from an assessment of the 'ground' from which it emerged (Osberg and Biesta 2007). This marks a significant epistemological shift away from representational understandings of knowledge and meaning.

A question that arises from this shift away from representational under- 
standings of knowledge and meaning is what this implies for a practice of schooling which, traditionally, has been organized around the idea that knowledge is representative of the real, relatively stable and can therefore be transferred from $A$ to $B$, in particular from one mind to another. One way in which this question has been taken up by educational theorists is in terms of how the emergence of meaning can be encouraged in the classroom. Davis et al. (2000), for example, ask how we as educators can make classrooms into places which are actively concerned with the emergence of meaning rather than places which are actively concerned with the transfer of meaning from teacher to student.

While examining this question is undoubtedly an important and necessary step towards reconceptualizing education along more contemporary epistemological lines, the main concern in this paper is not with how to facilitate the emergence of meaning in the classroom, but with the issue of what kinds of meaning are allowed to emerge in the classroom. This question is important because, if meaning is understood as emergent, and if educators wish to encourage the emergence of meaning in the classroom, then the meanings that emerge in classrooms cannot and should not be predetermined before the 'event' of their emergence. This raises the question of whether it is possible to maintain an emergentist conception of meaning in an 'educational' context, which in turn raises the question of what is meant by 'education'. In this regard we start by examining the terms education, learning, and enculturation.

\section{Education, learning, and enculturation}

People learn a great many things regardless of whether they are in school or not. It is therefore safe to say that human learning takes place all the time. But is this education? Many would argue that not all learning is educational. It is questionable, for example, whether unconsciously learning the habits of a particular culture through participating in that culture is educational. Education-so we might say-is different from unconscious enculturation in that it directs the kind of learning that takes place. In this way education purposely shapes the subjectivity of those being educated. It helps students to become responsible citizens, problem-solvers, people able to 'think for themselves', and so on. Thus one could say the function of education is to 'produce' certain kinds of subjectivities.

This 'shaping of subjectivity' is generally understood to be achieved through the curriculum (and the pedagogy 'supporting' the curriculum). With the concept of 'education' the notion of curriculum therefore acquires a very specific meaning. It becomes a course by means of which the subjectivity of those being educated is directed in some way. This understanding of the 
purpose of education seems to prevail amongst policy-makers, parents, and 'the general public', regardless of the complexity and 'messiness' of actual classroom practice, and regardless of teachers' individual pedagogical and epistemological beliefs. While teachers may be fully aware that much more takes place in the classroom than simply the transferal of a pre-given set of meanings into the mind of the learner (and indeed the lived experiences of classroom life make it impossible for teachers to hold such a view), teaching is invariably understood as having to be organized around particular purposes or goals that may be highly explicit (e.g. how to solve this kind of chemistry problem) or rather vague (e.g. to promote 'creativity' or 'problemsolving' abilities). This seems to imply that an educational curriculum is something which necessarily has a particular teleological intent, i.e. it must be directed towards some educational 'outcome'.

Our main point is that education, for the most part (and for whatever sociopolitical reasons), is organized around the idea that its primary purpose is to promote 'outcomes' in certain areas deemed important (for whatever reason), and the curriculum (i.e. the content and pedagogy supporting it) is the primary tool by means of which such competency is achieved. With this understanding of education the educator is considered to have a special responsibility to create learning environments (curricula) in which educational goals (regardless of how vaguely defined) can be met. If the outcomes are not met (for whatever reason), the educator is considered to have failed in his or her responsibility to educate.

As we see it, the main problem with this conception of education is that it means limits must be placed on the kinds of meaning that can emerge in a classroom. In creating learning environments (curricula) that aim to achieve certain educational outcomes educators are, in effect, expected to ensure that only 'legitimate' meanings emerge in the classroom-although they may know too well from their own experience that it is difficult if not impossible to delimit learning in this way. The attempt to place limits on the kinds of meaning that can emerge in a classroom can also be seen as an attempt to ensure that the subjectivity of those being educated is directed only in 'legitimate' ways-i.e. ways that are endorsed by those planning the educational programme and where failure to adopt these ways results in or is perceived as educational failure.

In this sense, while it is possible to distinguish education from unguided learning, education still remains a form of planned enculturation or 'training'. In contemporary multicultural societies, the difficulty with education as planned enculturation lies in the question of who decides what or whose culture should be promoted through education. ${ }^{3}$ The problem of 'educational enculturation' is therefore of considerable concern to theorists grappling with the issues raised by multiculturalism. It is precisely in this regard that we 
believe complexity-and in particular the logic of emer-gence-can be of use.

If we hold that meaning is emergent, and we insist on a strict interpretation of emergence (i.e. what emerges is more than the sum of its parts and therefore not predictable from the 'ground' it emerges from) ${ }^{4}$ then the idea that educators can (or should) control the meanings that emerge in the classroom becomes problematic. In other words the notion of emergent meaning is incompatible with the aims of education, traditionally conceived. Emergent meaning-if it exists-is incompatible with the idea of education as planned enculturation. The remainder of this paper is therefore taken up with the issue of how an emergentist conception of meaning would play out within the structures of schooling.

\section{The emergence of meaning in the classroom}

There are several pedagogies which, while not explicitly drawing on complexity as a theoretical or explanatory framework, can nevertheless be understood in terms of an emergentist conception of meaning. These are pedagogies which hold that knowledge and/or meaning is a 'creation' or 'invention'-an entity that emerges - rather than an entity that 'appears' at place $A$ (the mind of the student) because it has been transferred there from place $B$ (the textbook or mind of the teacher).

The idea that meaning can be 'created' in the classroom has, however, been regarded with a good measure of suspicion by many educators because of its association with the much criticized 'romantic' or 'anti-authoritarian' version of progressive education in which the role of the teacher is downplayed to the extent that it does not matter precisely what is learned as long as students are learning something. It has been argued again and again by conservatives and radicals alike that this pedagogy has no real 'educational' value. On the one hand, the 'untutored' approach puts people in the position of having to 'reinvent the wheel' before they can get anywhere, and, on the other, it allows for anything-goes inventionalism, where people can simply 'make things up' rather than deal with the 'reality' of the world. Dewey (1984: 59) himself-one of the foremost proponents of progressive education-claimed the 'romantic' approach was not only uneducational but 'really stupid'. It would seem, therefore, that for an emergentist conception of meaning to contribute to discussions about education it must not reduce the concept of education to untutored learning.

In another endeavour to bring schooling practices into line with contemporary epistemologies, Bereiter (1997, 2002a, b) draws on Popper's conception of 'World 3', the world of immaterial or 'abstract knowledge objects', - a world wholly created by the human intellect, which Popper (1972) also calls 'objective knowledge'-to address the issue of the creation 
of knowledge in the school. Bereiter (1997) points out that the advantage of treating knowledge as an artefact is that it can be understood as the product of a particular form of labour. Bearing in mind this understanding of knowledge, Bereiter then recommends a curriculum that entails designing classrooms as communities of practice whose work is with 'abstract knowledge objects'. Bereiter argues that even work conventionally categorized as unskilled involves a great deal of knowledge, but 'knowledge work' is different in that it not only uses knowledge but also produces it, i.e. abstract knowledge objects are the product of this type of work. This kind of work, Bereiter (1997: 298) claims, requires a special set of skills. He believes it is:

reasonable to assume that students who have had years of experience in explicitly working with knowledge will have an advantage over ones whose experience has been limited to the traditional kinds of scholastic learning and doing in which knowledge, as such [i.e. 'World 3' knowledge], is seldom the object of attention.

From an emergentist perspective, there are at least two problems with Bereiter's programme for 'knowledge production' in schools. First, for the process of knowledge production to occur it is necessary to assume that the meaning of a particular 'knowledge object' exists in a stable form such that the 'knowledge object' can be used like a 'building block' ${ }^{6}$ in the production of new abstract knowledge objects. This idea, however, is precisely what an emergentist epistemology denies. Because the meaning of any new knowledge that 'emerges' would be highly specific to the complex system from which it emerged, it follows that no 'knowledge object' can retain its meaning in a different situation. Knowledge objects cannot, in other words, be used as 'building blocks' (stable meanings) for future knowledge-building endeavours. Therefore, although Bereiter's pedagogy makes significant moves away from the more conventional idea that the objective of classroom teaching is to transfer knowledge into people's minds, it is nevertheless still reliant on an epistemology which holds that meaning is stable (rather than emergent). This means Bereiter's pedagogy is insufficient as a truly emergentist pedagogy.

Secondly, because of its reliance on the idea of knowledge as stable units of meaning, Bereiter's pedagogy constrains and prescribes the kind of new knowledge that can be produced or invented. The only knowledge that can be produced must be produced from a pre-existing range of stable units of meaning ('building blocks' of knowledge). It is only from such pre-existing and stable units of meaning (if they exist) that legitimate new knowledge can be created. The curriculum, in other words, is still pre-defined. For this reason, and despite its focus on creativity, Bereiter's pedagogy must still be understood as a form of planned enculturation. In fact it is a form of 'training'. But is education about training? 
In yet another endeavour to encourage the 'creation of meaning' in the classroom, Ulmer (1985) presents a pedagogy that he refers to as 'applied grammatology' (his preferred term for what he also calls a 'pedagogy of invention') which relies on a conception of meaning-making articulated by Derrida's (1976) 'theoretical' grammatology-more familiarly known as 'deconstruction'-which is remarkably close to what could be called a 'truly' emergentist conception of meaning-making (Osberg and Biesta 2007). Like an emergentist conception of meaning-making, 'theoretical' grammatology articulates the idea that every meaning 'always exceeds its concept' (UImer 1985: 162; emphasis removed). 'Applied grammatology' is therefore a useful way to understand what might be the pedagogical manifestation of a 'truly' emergentist conception of meaning-making.

Ulmer (1985) explains that a pedagogical presentation in a grammatological classroom would be one which is organized around the principle of the 'hieroglyph' (p. 265), this being an ideogrammatic/pictorial form of writing which provokes a response from the receiver (and this response is not only rational but also physiological and subconscious, e.g. knife plus heart $=$ sorrow). This idea draws on the notion, well developed in psychoanalysis, that the consciousness is affected before any meaning is formed. It is only through an addition to itself (the response of the receiver) that the hieroglyph becomes 'receivable'. Without such response it is 'unreceivable' (not understandable in itself). Because every presentation of a hieroglyph provokes a subjective response (a text) which adds itself to the presented (but unreceivable) text, every such presentation must be understood as bringing forth a wider reading of itself. It combines subjective and presented 'elements' in something different (a 'double text'). A grammatological pedagogy - so Ulmer claims-is therefore fundamentally inventionalistic or creative. It takes into account an emergentist mode of meaning-making, which is neither 'inner speech' ( subjective text) nor 'objective writing' (presented text) but an elaboration of both which always brings something new into the world ( pp. 157-188). It would seem, therefore, that in the grammatological classroom something entirely other than the reproduction of an idea in the mind of the student is taking place. What is taking place, Ulmer says, is 'inventio' ( $p . x i i)$.

Ulmer (1985: 225-264) considers the presentational strategies adopted by the German performance artist, J oseph Beuys (1921-1986), to be exemplary in illustrating how a grammatological pedagogy might actually be performed. Beuys has produced many stand-alone works, but while he was alive he would, in person, present 'explanations' of his art which were an integral part of the artworks themselves. According to Ulmer's (1985) interpretation, these presentations were designed to stimulate the audience to produce something out of themselves in response to this performance art (p. 251). What Ulmer tries to put across is that these performances did 
nottransfer a message; they were designed, rather, to move the spectatorby evoking associated memories-into producing a message. The message was produced as memories were explored, 'not to recover the past but ... in order to think with them into the future' ( $p .240$; emphasis added).

According to Ulmer, the evocative nature of Beuys's presentations generated rather than transmitted meaning. For Ulmer the meaning 'comes through' already contaminated by other layers of meanings. The effect is the genesis of something new, an inventio.

Ulmer's 'pedagogy of invention' opens a space for the elaboration of knowledge and does so in terms of a 'truly' emergentist conception of meaning-making. This, however, does not mean that Ulmer's pedagogy is no longer a practice of enculturation. Ulmer has designed a pedagogy to draw out 'creative' responses, believing he knows what it means to be 'creative'. In this sense his own understanding of what it means to be creative reappears in his students. Ulmer (1985: 173) labels this effect (which he does not notice in his own pedagogy) 'the undesirable pedagogical effect of discipleship' and describes it as a 'reproduction of the master's style'. This reveals that his pedagogy encultures students into his way of seeing the world. This problem in his work is connected to his understanding of the human subject.

Ulmer's subject is a discrete and isolated being that 'owns' the 'memories' (rational, mythic, unconscious, habitual, cultural, bodily, and so on) which it uses to create an inventio. In this sense it could be called an individualistic subject. It is only this assumption about the human subject that enables Ulmer to work out the principles of a pedagogy in which the subject ends up producing something new, an inventio. This assumption about the subject is, in other words, the raw material or foundation from which he works out his pedagogical scheme. He develops his 'pedagogy of invention' from a particular starting point, focusing on how, given this particular starting point, the human subject can be stimulated or 'incited' (Ulmer 1985: 314) to produce an inventio. This, however, immediately puts him in the position of having designed a pedagogy that will function to reproduce his own understanding of creativity. He has designed a pedagogy specifically to stimulate his notion of creativity (inventio) in those who are being educated. This is evident in the following remark:

[a pedagogy of invention is] intended not only to show people the principles of creativity and how to put them into practice but also ... to stimulate the desire to create (not necessarily in 'art', but in the lived, sociopolitical world) (p. 264).

Ulmer believes that he knows what the principles of creativity are and he wants to replicate this knowledge through education. The 'master' has, in other words, designed a pedagogy that will 'reproduce the master's style'. 
Although the objective of Ulmer's pedagogy is creativity itself (which masks its reproductive logic to some extent), this pedagogy can still be understood to be reproducing a particular understanding of creativity (i.e. one not necessarily held by all). As such, and despite his emergentist (or 'grammatological') epistemology, Ulmer's pedagogy is still governed by the logic of enculturation. Because, as we have argued, the intent to socialize is incompatible with the intent to encourage the emergence of meaning in the classroom, Ulmer's pedagogy cannot be considered a 'truly' emergentist pedagogy.

\section{Is a 'truly' emergentist pedagogy possible?}

Ulmer's work makes clear that simply designing a pedagogy that allows for the 'invention of meaning' in an emergentist sense does not release pedagogy from the logic of enculturation. Furthermore, his work also provides a clue as to where the 'discipleship' problem originates. It lies in having a preconceived idea of what constitutes the human subject. It is only in having a preconception of what the subject is that Ulmer is able to design a pedagogy that moves this subject towards a particular end (in this case towards being creative). In starting at a given point, and moving to another point, Ulmer (1985: x) prescribes a 'possible course of action' which is meant to channel the human subject in a pre-determined direction and hence close down other possibilities for the subject's emergence. It is this (the presence of a 'starting point') that produces 'the pedagogical effect of discipleship' with its underlying logic of enculturation.

In producing a pedagogy that reproduces his understanding of creativity, Ulmer's pedagogy shapes the subject in a certain way. In this regard, Ulmer's intent, like Bereiter's-who wants to teach young people how to be producers of legitimate 'abstract knowledge objects'-is to socialize those being educated into a particular way of being. While Bereiter is arguing for a pedagogy that produces people who can work with legitimate 'abstract knowledge objects' (which Popper called 'objective' knowledge), Ulmer is arguing for a pedagogy that produces people who are 'creative' (in Ulmer's sense of the word). The problem of course, is that in suggesting a 'possible course of action' both Ulmer and Bereiter are intentionally shutting down other possibilities for the emergence of human subjectivity or, to be more precise, of other kinds of human subjectivity, other ways of being human. In trying to control the product of the pedagogical intervention (i.e. in having a goal) they succeed in replicating their own understandings, i.e. they succeed in enculturing or socializing their students into a particular way of being that is decided in advance.

From the discussion so far we conclude that an emergentist conception of 
meaning is not sufficient to release education from the logic of socialization/ enculturation. Because the emergence of meaning cannot be separated from the emergence of human subjectivity we see that in trying to produce a certain kind of subject educators are still trying to reproduce a particular meaning (or set of meanings) which they believe is 'good' or 'right' or 'proper'. They are still socializing people into a particular way of being. At this point we could give up and say that it is not possible to free education from the logic of enculturation because being an educator is precisely about directing the subjectivity of others. To give up the attempt to direct the subjectivity of others is to give up education. There is another way out, however.

Because what ties education to the logic of enculturation is the idea that the goal of education should be to form a certain kind of human subject, what seems to be called for is a conception of human subjectivity which leaves open the question of what it means to be a human subject. This is where the notion of emergence is once again helpful. In the same way as an emergentist conception of meaning leaves open the question of the meaning of a meaning (including the notion of emergence itself), an emergentist conception of subjectivity leaves open the question of what it means to be a human subject. While an emergentist conception of meaning, on its own, opens different possibilities for pedagogy, it is unable to challenge the basic educational logic which wants to reproduce a certain (legitimate) form of knowledge in people. However, when an emergentist conception of subjectivity is also taken into account, pedagogy can no longer presume to reproduce pre-given meanings in people because to do so would necessitate a pre-knowledge of the constitution of the human subject. It is therefore only in the absence of pre-conceived assumptions about what constitutes a human subject that it becomes possible to educate without a pre-determined end, i.e. without trying to socialize people into a particular way of being.

The argument we are trying to make is that to use emergence to theorize education away from the logic of enculturation, it is necessary to use the concept of emergence on two levels. We need emergence on the level of meaning itself, but because meaning is attached to human subjectivity we also (at the same time) need it at the level of human subjectivity. In other words, we need the concept of emergence in a double sense. For this reason we shall now explore the notion of emergence as it applies to human subjectivity. We are concerned primarily with how not to close down possibilities for understanding the human subject in an educational context.

\section{Representational vs emergentist conceptions of human subjectivity}

Nancy (1991) has suggested that much of the theorizing about human subjectivity is a form of theorizing about the human subject that is premised 
on the question of what it is. This is a form of theorizing that is forever closing down possibilities for human subjectivity, rather than opening up possibilities or, at least, keeping possibilities open. It is a form of theorizing which says this is what a human subject is, not that, which closes down other possibilities. This, clearly, is a representational understanding of subjectivity. The question then is how to move from a 'representational' understanding of subjectivity to an 'emergentist' conception of subjectivity. An 'emergentist' perspective on subjectivity would leave open the question of what it means to be a human subject. It would support the notion that human subjectivity can emerge into that which is 'incalculable' from the perspective of the present. It would be concerned, in other words, with not closing down possibilities for human subjectivity, not representing the human subject as being either like this or like that.

Nancy (1991) explains that one way of not objectifying the human subject is to understand it in terms of who it is rather that what it is. He makes the point that when the human subject is understood in terms of what it is, it is understood as a kind of something, a case of something more general. He suggests furthermore that the question about human subjectivity-about what makes 'me' me-is a question about uniqueness. It would seem, therefore, that to 'understand' human subjectivity, it is necessary to focus on human beings in their uniqueness. More precisely, it is necessary to focus on who a subject is (in its uniqueness) rather than what a subject is (which is only ever what it is a case of). There is, however, a substantial difficulty in trying to understand the human subject as a unique 'who'. The problem, as Nancy (1991) points out, is that it is always possible to say that someone has become who they are (a particular kind of being) because of $x, y$, and $z$, because of something that lies behind them which has caused them to become who they are. The question of 'who' someone is therefore immediately reverts to a question of what it is that causes the 'who' to become 'what' it is. Nancy suggests that one way out of this dilemma is to understand who a subject is in terms of where it 'comes into presence' ( $p$. 7). According to Nancy this 'coming into presence' is always a unique event, something that 'takes place' ( $p .7$ ), and so does not reduce the subject to a case of something more general. For Nancy, the one who comes into presence is always 'one and unique in its coming' (Nancy 1991; emphasis added). The 'one' who comes into presence, in other words, only has a 'shape' in terms of the space where it comes into presence. It only has a 'shape' in terms of what it is not, i.e. in terms of the space itself. Because no two spaces can be the same, theone who 'comes' must also be completely unique (in the same sense as two spaces are unique).

The 'who' that Nancy is articulating is an emergentist who, in that it is a 'who' who 'comes into presence' in a space that cannot be reduced to either a spatial or a temporal location. The 'who' cannot be described in terms of what it is because every attempt to trace what it is (i.e. what lies behind the 
who) immediately explodes it into a myriad of relations and relationships that cannot be contained in the 'who'. This means if the 'who' of the subject is taken seriously (so that it does not relapse into the 'what' of the 'who') this 'who' must be understood as radically contingent. In this case it is not possible to know who emerges because the 'who' that emerges is partially constituted by an 'otherness' which is not the who that emerges.

One theorist whose understanding of human subjectivity comes particularly close to the idea of emergence is Hannah Arendt. While this is not the place to go into details, a brief description of her position is helpful for understanding what an emergentist conception of subjectivity might entail.

Arendt is specifically concerned, so we might say, with who a subject is, rather than with what a subject is. Her strategy for understanding the 'who' of the subject is to frame it in terms of human action which she describes as 'beginning something new' (Arendt 1958: 177). To act, for Arendt, is to begin. This she equates to the condition of natality (being born). For Arendt every human being is a beginning and a beginner (p. 177). When we begin something - when we act-we 'show ourselves' in the human world (as we do when we are born). Furthermore, we cannot refrain from acting, from making beginnings (any more than we can refrain from being born). However, because we live with others-i.e. in a 'public' or 'political' space- our beginnings are always frustrated by the beginnings of others whose beginnings are likewise frustrated by our own beginnings. We are, in other words, never in a position in which 'one man remains master of his doings from beginning to end' (p. 220).

This frustration of the 'purity' of our beginnings is, nevertheless, the condition of possibility for us to come into the world as distinctly unique beings. This is because the contamination of each one of our beginnings by the beginnings of others has the effect of making each and every beginning completely unique. Because every time we make a beginning we show ourselves and because every beginning we make is completely unique (because contaminated by the beginnings of others), Arendt can claim that when we make a beginning - when we act-we show ourselves in our unique distinctness. Arendt insists, however, that the disclosure of our unique identity (through action) is not a disclosure of a pre-existing identity. Because our actions are always contaminated by the actions of others we are never the sole author or producer of our beginnings and therefore also not the sole author of the 'who' that we reveal through these beginnings. As Arendt ( p. 180) comments, 'Nobody knows whom he reveals when he discloses himself in deed or word'. The 'who' that we reveal is always radically contingent on other 'who's' with whom we live. 
This means we are who we are only by virtue of others who frustrate the 'purity' of our actions. If we try to preserve the purity of our actions (by not being with others, or by forcing others to do what we want them to do, thereby preventing them from making their own beginnings) we deprive ourselves of the opportunity to come into presence in our unique distinctness. In this regard, 'action'-i.e. making a beginning with others who frustrate our beginnings-is the condition of possibility for becoming a unique 'who'. For Arendt, who we are is not something that exists before the other, nor is it something that appears because of the other. Rather it appears only in relation to the other (neither before nor after). This understanding of subjectivity suggests that being with others-with those who are different from ourselves and whose beginnings frustrate our own beginnings-is the only condition in which subjectivity can take place, the only condition in which we can show ourself in our uniqueness, i.e. as a 'who' instead of only a 'what'. Even the word 'self' is problematic, however, for it suggests a containment that is not there. As Caputo (1987: 289) remarks:

the word 'self' will not do, because ... [t] he 'self' is something which we define in terms of its self-identity. Yet what seems to characterize 'us' above all is non-identity. ... The self is precisely not that which always abides in itself. ... The 'self' is much more a place of disruption, irruption, solicitation.

An emergentist understanding of human subjectivity, in which the 'self', as Foucault observed, 'is not one but split, not sovereign but dependent, not an absolute origin but a function ceaselessly modified' make it very difficult indeed to theorize education from the conventional 'foundations', where theories of education are built upon the notion that teachers and learners are objects which can be manipulated to bring about certain educational outcomes. Traditional theories of education are theories about how to teach students (as objects) and theories about how students (as objects) can learn (which of course affects how they should be taught).

The emergentist challenge to this conventional logic does not, however, mean that it is no longer possible to theorize about education. While emergentist conceptions of subjectivity disrupt theorizing about the objects of education (teachers and learners), they facilitate theorizing about the space in which the subject 'comes into presence' (Biesta 2006: 34), i.e. the 'gap' between teachers and learners (Biesta 2004). Because it is possible to theorize about this space-which could just as well be called a 'space of emergence' - this 'space' or 'gap' can therefore be used as a 'foundation' for educational theorizing (Biesta 1999). This 'foundation', however, is not a foundation in the usual sense of the word. Because the space in which the subject emerges is a space of radical contingency (Biesta 2006: 33-54), it is 
a space in which the notion of foundations has no place:

If this [gap] is the location of education, if this is where education literally 'takes place', then a theory of education should be a theory about the interaction between the teacher and student. A theory of education is, in other words, a theory about the educational relationship. It is not about the 'constituents' of this relationship (i.e. the teacher and the learner) but about the 'relationality' of the relationship. (Biesta 2004: 13)

It appears there is hardly any work that uses an emergentist perspective on subjectivity in order to theorize education. When the notion of curriculum (or 'education') is understood not as the means by which students (as objects) are 'encultured' in certain pre-selected ways of being (the norm in current mainstream educational policy), but as a 'space of emergence'-a space where the human subject is continuously emerging or 'coming into presence' (Biesta 2006: 33) -this introduces a language of education in which the messiness of classroom practice and the unpredictability of learning can be made more central to understandings and justifications of teaching practices, so that it is no longer necessary to hide it away as something 'that all good teachers know but that nonetheless cannot speak of'. The curriculum as a space of emergence provides a language of education in which what was previously considered deviant (such that teachers would struggle to give it a place) becomes normal and can actually be seen as central to educational practices that claim to be educational rather than simply practices of socialization. In particular, this understanding of curriculum redefines educational responsibility in a way that acknowledges that the unpredictability, creativity, and messiness of the lived experience of classroom practice is the result of good teaching, not a sign of its failure per se. The next section, therefore, provides an account of what is specific about the task-or responsibility-of the teacher when the curriculum is conceived of as a space of emergence.

\section{Educational responsibility in the space of emergence}

The first thing to notice about the curriculum as a 'space of emergence' is that it is not a space of common ground. Because human subjectivity emerges only when one acts with others who are different (Arendt 1958, Biesta 2006: 33-54), this means education only takes place where 'otherness'-being with others who are different from us-creates such a space. In this sense it is the plurality of the 'space of emergence' that educates, not the teacher (Biesta 2006: 13-32).

However, if plurality is the condition of possibility of education, then this challenges the conventional logic of schooling whereby everything possible is 
done to reduce the differences between the teacher and those being educated on the one hand, and the differences between the various individuals being educated by the teacher (e.g. in terms of age, gender, ability, interests, etc.) on the other. The idea of a 'space of emergence' suggests that difference must be maintained in the classroom. Any reduction of such difference prevents education from taking place. Theorizing education from an emergentist logic means the classroom must be a space of difference, of otherness, a 'public' or 'worldly space' (Biesta 2006: 97). Educators, then, have a responsibility 'to make sure that there are at least opportunities within education to meet and encounter what is different, strange, and other' (Biesta 2006: 69). With the increasing balkanization of communities and the creation of 'quasi-public spaces such as the shop-pingmall and the high-security university campus-spaces that might look public but actually are organized around private interests' (Biesta 2006: 113) -it could happen that schools become the only places left for otherness and plurality.

Another thing to take into account when theorizing education as a 'space of emergence' is that such a space is not good at bringing about the convergence of individual perspectives. It is the case, rather, that the plurality of the space of emergence encourages the emergence of unique individuals (rather than a collection of objects all belonging to the same class or category). If, as educators, we are responsible for maintaining a space of emergence, then we are also responsible for not attempting to make people more similar, not attempting to initiate or socialize people into a common way of being (Biesta 2006). As educators, we are responsible, instead, for enabling people to become more unique, more irreplaceable as singular human beings. The educational responsibility, in other words, is to ensure that everyone being educated is able to become an irreplaceable someone. This is very different from conventional understandings of education where curricula with fixed goals are imposed on people such that there is little scope for any of those being educated to develop in an idiosyncratic way. In fact the very purpose of the (conventional) curriculum has been to 'iron-out' these idiosyncrasies, to iron out the 'kinks' so that those being educated can develop in the 'right' way. Such curricula are designed to produce (train) interchangeable units. From an emergentist perspective such curricula can only be seen as un-educational.

Yet another consequence of understanding education as taking place in a 'space of emergence' is that it becomes necessary to acknowledge that situations in which it is difficult or impossible to become the master of one's own actions, i.e. where it is difficult to achieve what one wants to achieve, are the very situations that make education possible (Biesta 2006: 73-95). This is because from an emergentist perspective it is only through the frustration of one's intentions that one can 'come into presence' as a singular being. This frustration of intentions-that which makes education difficult or 
even impossible-must therefore be understood as the condition that makes education possible (Biesta 2006: 73-95). This is contrary to conventional educational logic where it is believed necessary to remove any obstacles to reaching the desired educational goal so that the goal can be reached as quickly and easily as possible. With an emergentist conception of education it becomes possible to see that this logic is detrimental to a human being 'becoming someone'. The responsibility of the educator in a 'space of emergence' is not to ensure a desired end is reached with a minimum of fuss, but rather always to complicate the scene, to unsettle the doings and understandings of those being educated, in order to keep the way open.

The space of emergence is therefore not an easy space to be in. It is difficult and provocative, and often uncomfortable. There is even a certain 'violence' in this educational space (Biesta 2006: 26). It is 'violent' because all those in the space of emergence are faced with difficult and disturbing challenges that bring forth unforeseen (and not always pleasant) changes (Biesta 2006: 29). It is violent also because those in the space are forced to take a position and thereby show themselves. By engaging in education, one is therefore placing oneself at risk (and this applies to both teachers and learners). One does not know, cannot know, what will happen, only that something will happen. In a space of emergence we, as educators, therefore have a responsibility not to deny the violence involved in coming, or maybe we should say calling, into presence.

\section{Conclusion: keeping the play in play}

Emergentist epistemologies challenge the idea that meaning is 'acquired' and suggest instead that meaning is continuously made and remade through engagement with our world. Meaning is therefore not something one can ever 'have'. However, because meaning-making is inseparable from human subjectivity, and because education is uniquely concerned with the 'shaping' of human subjectivity, when emergence is used to theorize education it is necessary to apply the notion of emergence not only to knowledge and meaning but also to human subjectivity. When this is done it becomes possible to understand human subjectivity not in terms of an object or entity but in terms of the space in which the subject emerges or 'comes into presence' as a singular being. However, in giving up the idea of students as objects, it is also no longer possible to conceive of education as guiding these objects from point $A$ to point $B$, for there is no longer a 'point $A$ ' (i.e. a particular kind of object or starting place) from which to begin this endeavour. This, in turn, suggests that the notion of 'educational responsibility' must be reconceived.

When the logic of emergence is used-at the level of knowledge and the level 
of human subjectivity-to 'rethink' education it is no longer possible to understand 'educational responsibility' as being to bring about the successful transit of an object (a student) from point $A$ to point $B$, or assisting students in reaching a pre-determined destination. With the logic of emergence it becomes possible to understand educational responsibility as continuously complicating the scene, thereby making it possible for those being educated to continue to emerge as singular beings. Educational responsibility is about continuously re-opening subjectivity, unsettling closures, and unpicking 'destinations'.

However, as educators we are responsible not only for unsettling the student's closures and thereby calling the student into presence. We are also responsible for the singularity, for the uniqueness of who is called into presence (Biesta 2006: 33-54). We must acknowledge that our actions call up a particular who. We cannot educate without in some way shaping the 'who' that is called into presence. This is not only unavoidable, but any attempt to avoid it would be an act of neglect, for it would mean leaving the student alone (i.e. not educating). In this sense educators are responsible for a closure (a particular 'who' is called into presence through our actions) at the same time as being responsible for the opening of this 'who'. The educational responsibility must therefore be understood in a double sense. As educators we are responsible not only for the unsettlement (violating, opening) of the one called, but also for the particular one called (which is a closure). In other words we are responsible, at the same time, for the opening and closing of subjectivity. We are responsible for keeping the play in play. This understanding of education is very far from understandings which suggest that education is about enculturing people into a way of being decided in advance, where those who do not manage to enculture or become encultured in the approved way are considered educational failures.

\section{Acknowledgements}

A version of this paper was presented at the 3rd Complexity Science and Educational Research Conference (2005), Loranger, LA, USA. Thanks to Chris Breen for letting us use in this paper part of the title of the paper he presented at this conference.

\section{Notes}

1. See Biesta and Burbules (2003), Biesta and Osberg (2007), Cilliers (1998) and Osberg et al. (in press)

2. See also Davis (2004) and Davis and Sumara (2006). 
3. See Apple (1993).

4. See Osberg and Biesta (2007).

5. Popper's 'World 1 ' is the physical world and 'World 2 ' is the experiential or subjective world.

6. Although it should be mentioned that Bereiter himself avoids using the term 'building block'

to describe these stable units of meaning.

7. See Biesta (2006).

8. See Biesta (2006) for a detailed account.

9. Foucault, interview material, May 1969, quoted in Dreyfus (2004).

10. For an exception, see Biesta (2006).

\section{References}

Apple, M. W. (1993) Official Knowledge: Democratic Education in a Conservative Age (New York: Routledge).

Arendt, H. (1958) The Human Condition (Chicago: University of Chicago Press).

Bereiter, C. (1997) Situated cognition and how to overcome it. In D. Kirshner and J. A. Whitson (eds), Situated Cognition: Social, Semiotic, and

Psychological Perspectives (Hillsdale, NJ: Lawrence Erlbaum Associates), 281-300.

Bereiter, C. (2002a) Education and Mind in the Knowledge Age (Mahwah, NJ: Lawrence Erlbaum Associates).

Bereiter, C. (2002b) Artifacts, canons, and the progress of pedagogy: a response to contributors. In B. Smith (ed.), Liberal Education in a Knowledge Society (Chicago: Open Court), 223-244.

Biesta, G. (1999) Radical intersubjectivity: reflections on the 'different' foundation of education. Studies in Philosophy and Education, 18(4), 203220.

Biesta, G. (2004) 'Mind the gap!' Communication and the educational relation. In C. Bingham and A. M. Sidorkin (eds), No Education Without Relation (New York: Peter Lang), 11- 22.

Biesta, G. (2006) Beyond Learning: Democratic Education for a Human Future (Boulder, CO: Paradigm Publishers).

Biesta, G. and Burbules, N. C. (2003) Pragmatism and Educational Research (Lanham, MD: Rowman \& Littlefield).

Biesta, G. and Osberg, D. (2007) Beyond re/presentation: a case for updating the epistemology of schooling. Interchange, 38(1), 15-29.

Caputo, J. D. (1987) Radical Hermeneutics: Repetition, Deconstruction, and the Hermeneutic Project (Bloomington, IN: Indiana University Press).

Cilliers, P. (1998) Complexity and Postmodernism: Understanding Complex Systems (London: Routledge).

Davis, B. (2004) Reinventions of teaching: expanding the space of the possible. In B. Davis (ed.), Inventions of Teaching: A Genealogy (Mahwah, NJ : Lawrence Erlbaum Associates), 179- 184.

Davis, B. and Sumara, D. J. (2006) Complexity and Education: Inquiries into Learning, Teaching, and Research (Mahwah, NJ: Lawrence Erlbaum Associates).

Davis, B., Sumara, D. J. and Luce-Kapler, R. (2000) Engaging Minds: 
Learning and Teaching in a Complex World (Mahwah, NJ: Lawrence Erlbaum Associates).

Derrida, J. (1976) Of Grammatology, trans. G. C. Spivak (Baltimore, MD: J ohns Hopkins University Press).

Dewey, J. (1984 [1926]) Individuality and experience. In J. A. Boydston (ed.), Later Works of J ohn Dewey, 1925-1953, Vol. 2: 1925-1927

(Carbondale, IL: Southern Illinois University Press), 55-61.

Dreyfus, H. L. (2004) Heidegger and Foucault on the subject, agency and practices.

Department of Philosophy, University of California, Berkeley, CA, USA.

Available on-line at:

http://socrates.berkeley.edu/ hdreyfus/html/paper_heidandfoucault.html, accessed 15 April 2007.

Nancy, J.-L. (1991) Introduction. In E. Cadava, P. Connor and J.-L. Nancy (eds), Who Comes After the Subject? (London: Routledge), 1-8.

Osberg, D. and Biesta, G. J. J. (2007) Beyond presence: epistemological and pedagogical implications of 'strong' emergence. Interchange, 38(1), 31-51.

Osberg, D., Biesta, G. and Cilliers, P. (2007) From representation to emergence: complexity's challenge to the epistemology of schooling. Educational Philosophy and Theory in press.

Popper, K. R. (1972) Objective Knowledge: An Evolutionary Approach (Oxford: Clarendon Press).

Ulmer, G. L. (1985) Applied Grammatology: Post(e)-pedagogy from Jacques Derrida to Joseph Beuys (Baltimore, MD: Johns Hopkins University Press). 